The identification of X Persei with an X-ray source would lend considerable support to Blaauw's suggestion.

I thank Professor Giacconi for permission to quote his results in advance of publication.

David Dunlap Observatory, Sidney VAN DEN Bergh

University of Toronto,

Richmond Hill,

Ontario

Received December 24, 1971.

${ }^{1}$ Hoffleit, D., Catalogue of Bright Stars (Yale University Observatory, New Haven, 1964).

${ }^{2}$ Blaauw, A., Bull. Astron. Insts. Netherlands, 15, 265 (1961).

\section{Morphology of Carbon Fibres}

IT has been suggested recently that the morphology of high modulus carbon fibres involves sheet-like elements arranged concentric to the fibre axis ${ }^{1,2}$, somewhat in the manner of growth rings in trees. We have confirmed this proposal for PAN-based high modulus carbon fibres, supplied by the Celanese Research Company.

Scanning electron micrographs were obtained on a JEOL JSM-2 microscope operated at $25 \mathrm{kV}$. Fig. 1 shows a scanning

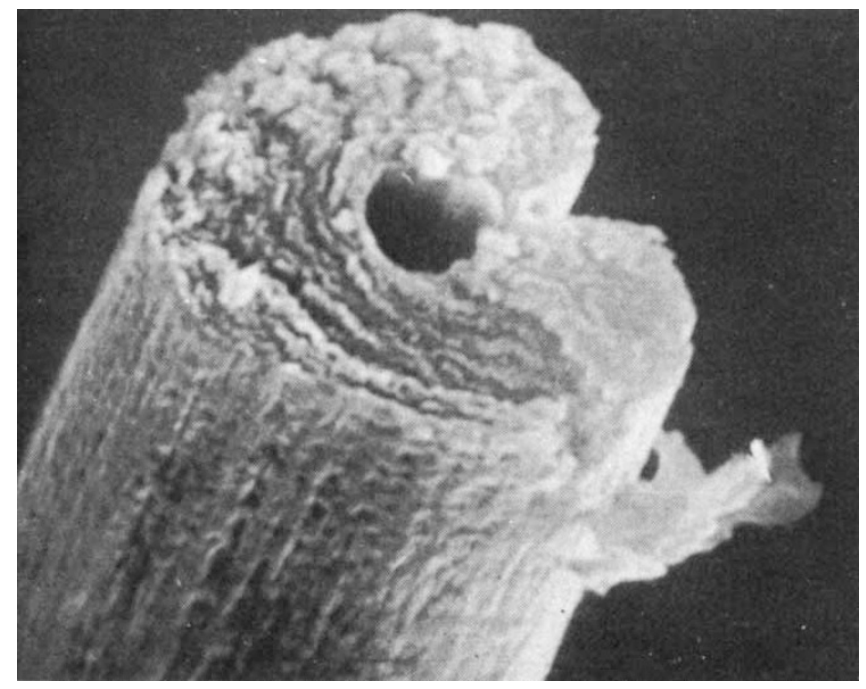

Fig. 1 Carbon fibre broken in tension $(\times 3,750)$.



Fig. 2 Carbon fibre broken in torsion $(\times 2,250)$. electron micrograph of a fibre broken in tension, in which sheets of the order of $1000 \AA$ thick can be seen. Such a structure was found to be more easily discerned in fibres such as that shown in Fig. 1, which contained a large internal flaw, but this structure was by no means confined to this type of fibre. The structure was demonstrated by breaking the fibre in torsion. In these conditions a major component of the applied strain was taken up as shear between adjacent planes and resulted in a breakdown of the fibre into the sheet-like elements as shown in Fig. 2. This indicates that the cohesive forces within these sheet-like units are greater than those between them.

These sheets are being investigated by transmission electron microscopy and their influence on the mechanical properties of the fibre is being evaluated.

We thank the Australian Atomic Energy Commission for support.

Murray Stewart

M. Feughelman

School of Textile Technology,

University of New South Wales,

PO Box 1,

Kensington, New South Wales 2033

L. M. GILLIN

Aeronautical Research Laboratories,

Fishermen's Bend,

Victoria 3207

Received November 16, 1971.

1 Gillin, L. M., Proc. Symposium Modern Ceramic Fibre Composites, Canberra (1971).

2 Wicks, B. J., Coyle, R. A., and Gillin, L. M., Tenth Biennial Carbon Conference, Lehigh University (1971).

\section{BIOLOGICAL SCIENCES}

\section{Heavy Lysozymuria after X-Irradiation of the Spleen in Human Chronic Myelocytic Leukaemia}

By electrophoretic analysis we have found large quantities of an exceptionally basic protein in the urine of five out of seven consecutive cases of chronic myelocytic leukaemia. In four cases the specific proteinuria occurred when induction of remission was achieved after $\mathrm{X}$-irradiation directed against the enlarged spleen. In one case the protein was found before X-ray therapy, but irradiation evoked an increasing protein response. The proteins have been isolated and characterized as relatively low molecular weight constituents with the enzymatic properties of lysozyme.

Twenty-four hour samples of urine were collected and the lysozyme activity was estimated by a slight modification of the method of Osserman and Lawlor ${ }^{1}$. The normal range of activity was from $0-2 \mu \mathrm{g} \mathrm{ml} .^{-1}$. The urine of patients suffering from chronic lymphocytic and acute lymphoblastic leukaemia, acute myelogenous leukaemia and chronic myelocytic leukaemia in general showed activities within the normal range, in agreement with the results of others ${ }^{1,2}$. High levels of urinary lysozyme activity were observed in acute monocytic and myelomonocytic leukaemia ${ }^{1-3}$.

After the first course of X-ray therapy, in doses of 4-5x $100 \mathrm{r}$., a rapid drop in the number of peripheral leucocytes was observed, with simultaneous increase of urinary lysozyme activity to values in the range of $260-700 \mu \mathrm{g} \mathrm{ml} .^{-1}$, and was still increased after 45 days. With the development of prolonged 